\title{
Impactos de adoecimento de longa duração: experiência de adultos jovens com Leucemia Mieloide Aguda
}

\author{
Impacts of long-term illness: experience of young adults \\ with Acute Myeloid Leukemia
}

Reni Aparecida Barsaglini ${ }^{1}$

Beluci Bianca Nunes de Siqueira Soares ${ }^{1}$

${ }^{1}$ Instituto de Saúde Coletiva. Universidade Federal de Mato Grosso. Av. Fernando Correa da Costa $s / n^{\circ}$ Campus Universitário CCBSIII Boa Esperança. 78060-900 Cuiabá MT Brasil. barsaglinireni@gmail.com
Abstract This article analyzes the tangible and intangible impacts involved in the experience of young adults diagnosed with a long-term illness, namely Acute Myeloid Leukemia. It follows on from broader research, inspired by the Phenomenology of Alfred Schutz. The data were obtained through in-depth interviews with four young adults, aged between 20 and 28, who were in the maintenance phase of cancer treatment between November 2013 and January 2014 in the State of Mato Grosso. The results focus on striking aspects of the impacts of the experience during the process of becoming aware of the illness in which the diagnosis provoked feelings mobilized by ideas regarding a serious illness. This is followed by the impacts on appearance due to the treatment, especially hair loss and day-to-day coping strategies, as well as weight gain or loss. Finally, there is the marked impact of the imminence of death due to the lethality of the disease and the testimony of the occurrence in friends and family, but also for the survivors. The impacts are the effects and transformations in the lives of people and their relations and evoke (re)actions, however, they are diluted in the experience composing it, and not being homogeneous, its approach addresses the singularity encountered in contextualized biographies.

Key words Acute Myeloid Leukemia, Experience of illness, Chronic illness
Resumo O presente artigo analisa os impactos materiais e imateriais imersos na experiência de adultos jovens com um adoecimento de longa duração - Leucemia Mieloide Aguda. Decorre de pesquisa mais ampla, inspirada na Fenomenologia de Alfred Schutz. Os dados foram obtidos por entrevistas em profundidade com quatro jovens, de 20 a 28 anos, em fase de manutenção no tratamento oncológico, entre novembro de 2013 a janeiro de 2014, em Mato Grosso. Os resultados enfocam aspectos marcantes dos impactos na experiência como o processo de descoberta da enfermidade em que o diagnóstico provocou sentimentos mobilizados por ideias sobre uma doença grave. Seguem-se os impactos na aparência devidos ao tratamento, sobressaindo a queda de cabelo e as estratégias cotidianas de enfrentamento, bem como o aumento ou a perda de peso. Por fim, é marcante o impacto da iminência da morte diante da letalidade da doença e o testemunho da ocorrência em pessoas conhecidas, colocando-a como possibilidade concreta para si, mas também como sobreviventes. Os impactos são os efeitos e as transformações na vida das pessoas e seu entorno e evocam (re) ações, contudo, diluem-se na experiência compondo-a, e não sendo homogênea, sua abordagem privilegia a singularidade inscrita em biografias contextualizadas.

Palavras-chave Leucemia Mieloide Aguda, Experiência de adoecimento, Adoecimento crônico 


\section{Introdução}

Neste artigo direcionamos o olhar à compreensão de como o sujeito vivencia um adoecimento específico, atribuindo significados através das ações, interações e (re) interpretações, desenvolvendo novas maneiras de lidar com a situação de adoecido. Pautado pela abordagem da experiência, entende-se o adoecimento como processo subjetivo que envolve interpretações e significados na experiência que se dá na vida cotidiana, mas, também, intersubjetivo que pressupõe parâmetros ou quadros de referência internalizados por meio de interação e comunicação com os outros - daí a sua dimensão situacional e coletiva porque ligada a projetos e contextos culturais e históricos concretos ${ }^{1,2}$.

Orientando-se pelo método qualitativo em saúde, nos aproximamos da corrente teórica fenomenológica que propõe descrever o "que se passa" sob o ponto de vista daqueles que vivem dada situação concreta e como, por meio desse processo, indivíduos e grupos sociais concebem reflexivamente ou representam o seu mundo" ${ }^{2}$. Corrobora tal ideia o entendimento de que a experiência é "(...) o que nos passa, o que nos acontece, o que nos toca. Não o que se passa, não o que acontece, ou o que toca. A cada dia se passam muitas coisas, porém, ao mesmo tempo, quase nada nos acontece"s. Assim, somente aquilo que faz sentido entrará no campo da consciência, sendo que as maneiras de sentir a realidade não dependem exclusivamente de uma fisiologia ${ }^{4}$, sendo pautadas, também, pelo contexto, ainda que deixe margem à sensibilidade individual.

Entre os modos de adoecer, destacamos o adoecimento de longa duração o qual perdura, é incerto, múltiplo, desproporcionalmente intrusivo, carreando consequências na vida cotidiana do sujeito e seu entorno, com implicações de caráter médico, mas, sobretudo, social que requerem paliativos $^{5,6}$. Trata-se de denominação afeita à literatura socioantropológica brasileira, em distinção ao "crônico" devido às conotações biomédicas e respectivas limitações desta concepção mais restrita aos aspectos objetivos da doença, ainda que a primeira não a recuse no estudo da experiência. Autores pioneiros que investigaram a experiência deste tipo de adoecimento preocuparam-se com os impactos na vida dos adoecidos, familiares e profissionais de saúde e como os manejavam empreendendo diferentes tipos de trabalho abordados no seu enfrentamento cotidiano ${ }^{7}$.

Tais impactos podem ser de ordem material e imaterial, simbólico. Na primeira estariam às condições de subsistência, as características das pessoas, moradia, trabalho, meio ambiente e produção; e na segunda, os valores, símbolos, significados, sentidos, crenças e representações; lembrando que este sistema não é estático, ou seja, o material é modelado pelo imaterial e vice-versa, num sistema circular8.

Assim, consideramos que os impactos do adoecimento por leucemia envolvem a situação biográfica e esta decorre do ambiente social e cultural, do status e papel exercido em dado contexto, como também a posição moral e ideológica do adoecido. Trata-se da história pessoal no mundo social em que há a sedimentação de experiências anteriores ou estoque de conhecimento, os propósitos futuros de cada sujeito 9 . Neste sentido, concorda-se que:

A enfermidade crônica afeta todos os aspectos da vida, porém o impacto sentido por cada indivíduo pode ser diferente devido às características da personalidade de cada um, em que os sistemas de apoio têm seu lugar, além de outros fatores de influência e que são únicos para cada indivíduo ${ }^{10}$ (tradução livre).

Dentre as doenças crônicas, destacamos a leucemia mieloide aguda - LMA, devido ao desenvolvimento lento, às múltiplas causas, a longa duração (superior a seis meses), exigindo cuidados prolongados e contatos, amiúde, com serviços e profissionais de saúde. Daí a relevância deste tipo de estudo e cuidado, pois traz a perspectiva do sujeito que vivencia o adoecimento de longa duração. Diante disso, o presente texto tem como objetivo analisar os impactos materiais e imateriais imersos na experiência de adultos jovens adoecidos por LMA e constitui recorte de pesquisa mais ampla ${ }^{11}$.

\section{Procedimentos metodológicos}

O estudo foi desenvolvido em Mato Grosso, de $11 / 2013$ a $01 / 2014$. Os participantes foram identificados junto ao ambulatório de Oncologia e Hematologia de um hospital de referência no estado. Os critérios de inclusão foram: residir em Mato Grosso; estar na fase de manutenção por ser branda, com pequenas doses de quimioterápicos via oral, supondo-se que o sujeito esteja menos fragilizado fisicamente e pode rememorar momentos anteriores; ter idade entre 20 a 28 anos, pois nessa faixa etária (adulto jovem) é comum ocorrerem significativas definições (escolarização, entrada no mercado de trabalho, constituição de família), tornando mais marcantes e identificáveis os impactos na vida. 
Os critérios de exclusão foram: dificuldades na fala e na comunicação oral, sofrimento mental, pois dificultariam a entrevista, bem como aqueles com mal-estar e agudização.

Foram realizadas três entrevistas com cada um dos quatro sujeitos, valendo-se de roteiro temático aprofundado a partir do processo de descoberta, tratamento e seus impactos. Os relatos, que constituem memória e interpretações do vivido trazido como experiência/o que marcou (nunca acessamos ela em si), foram registrados em áudio, transcritos e o material submetido à análise temática identificando seus núcleos de sentido, compondo categorias e temas ${ }^{12}$.

Os dados foram organizados enfocando os impactos mais significativos diluídos na experiência do adoecimento, os quais incidem no processo de descoberta da enfermidade, na aparência e nas iminências da morte.

A pesquisa foi aprovada pelo Comitê de Ética do Hospital Universitário Julio Müller, conforme a resolução no ${ }^{\circ}$. 466/2012 do Conselho Nacional de Saúde, de modo que todos os nomes próprios usados são fictícios.

\section{Conhecendo os sujeitos do estudo}

Algumas características da LMA contribuíram para o restrito numero de participantes como: alta letalidade, agudização de sintomas decorrentes de tratamento, óbito, recusa. Assim, como mostra o Quadro 1, o estudo foi composto por dois sujeitos do sexo masculino e dois do feminino, com 24, 27, 22 e 26 anos e que tiveram o diagnóstico da leucemia com 16, 17, 17 e 21 anos, respectivamente.

A escolaridade é baixa (três com ensino médio completo e um cursando) e ocupações de pouca qualificação. A entrada do jovem no trabalho é um divisor de águas, com ocupação de pouco prestígio e baixa remuneração, passando a serem situações excludentes, o estudo e o trabalho ${ }^{13}$. Contudo, não é comum as escolaridades longas comporem os projetos de vida de segmentos populares, devido às perspectivas mais imediatistas da estabilidade econômica, inserção no mercado de trabalho e constituição de família ${ }^{14}$.

Considerando que os sujeitos tiveram o diagnóstico há quatro anos e/ou mais, ao lado da alta letalidade da LMA, pode-se dizer que eles são sobreviventes do câncer ${ }^{15,16}$, pois terminaram o tratamento quimioterápico e retomaram (com ajustes) seus papéis sociais, inclusive como alunos o que nos pareceu atestar a normalidade reconstruída.

Os sujeitos são usuários do Sistema Único de Saúde, sendo que três residem em no interior de Mato Grosso (aproximadamente $300 \mathrm{Km}$ da capital) e um é do Pará. As respectivas cidades não possuem serviços oncológicos locais, sendo necessário o referenciamento aos grandes centros urbanos, como é o caso, podendo gerar dificuldades e amplificar o impacto do adoecimento.

Três entrevistados estavam fora do tratamento quimioterápico, ou seja, passaram pelas quatro fases previstas em protocolo, a saber: indução (de eliminação de maior número de células leucêmicas), consolidação (uso intensivo de substâncias não usadas anteriormente); reindução (repetição dos

Quadro 1. Perfil dos sujeitos entrevistados quanto ao estado civil, idade, escolaridade, renda familiar, número de pessoas residentes na casa, ocupação, naturalidade, cor, idade do diagnóstico e situação atual em relação ao tratamento.

\begin{tabular}{|c|c|c|c|c|c|c|c|}
\hline Nome fictício & Estado civil & Idade atual & \multicolumn{2}{|c|}{ Escolaridade } & \multicolumn{2}{|c|}{ Renda familiar (SM) ${ }^{\mathrm{a}}$} & $N^{o}$ de pessoas na casa \\
\hline Fábia & Separada & 26 & \multicolumn{2}{|c|}{ Ensino Médio } & \multicolumn{2}{|c|}{ Até 6} & 3 \\
\hline Fabiana & Casada & 22 & \multicolumn{2}{|c|}{ Ensino Médio } & \multicolumn{2}{|l|}{ Até 2} & 2 \\
\hline Fabrício & Solteiro & 27 & \multicolumn{2}{|c|}{ Ensino Médio } & \multicolumn{2}{|l|}{ Até 3} & 3 \\
\hline Felipe & Separado & 24 & \multicolumn{2}{|c|}{ Cursando Ensino Médio } & \multirow{2}{*}{\multicolumn{2}{|c|}{$\begin{array}{c}\text { Idade ao receber o } \\
\text { diagnóstico }\end{array}$}} & 2 \\
\hline Nome fictício & \multicolumn{3}{|l|}{ Ocupação } & Cor $^{\mathrm{b}}$ & & & $\begin{array}{c}\text { Situação atual de } \\
\text { tratamento }\end{array}$ \\
\hline Fábia & $\begin{array}{l}\text { Supervisora d } \\
\text { vendas }\end{array}$ & $\begin{array}{l}\text { Tangará } \\
\text { MT }\end{array}$ & da Serra/ & Branca & 21 & $\begin{array}{l}\text { Fase } \\
\text { mar }\end{array}$ & $\begin{array}{l}\text { de transição entre } \\
\text { nutenção e F. T. }\end{array}$ \\
\hline Fabiana & Do lar & Várzea G & rande/MT & Branca & 17 & F. T. & C. há 2 anos \\
\hline Fabrício & Office boy & Novo $\operatorname{Pr}$ & gresso/PA & Pardo & 17 & F. T. & C. há 6 anos \\
\hline Felipe & Assistente $^{\mathrm{e}}$ & Sinop/M & & Pardo & 16 & F. T. & C. ${ }^{c}$ há 4 anos \\
\hline
\end{tabular}

a Salário mínimo equivalente a R\$678,00 em 2013. ${ }^{\mathrm{b}}$ Auto referida. ${ }^{\mathrm{c}}$ Fora de Tratamento. 
medicamentos da fase de indução da remissão) e manutenção (tratamento brando e contínuo por vários meses) ${ }^{17}$. Segue-se após, um período médio de seis a oito anos denominado "fora de tratamento", com consultas médicas e exames periódicos.

\section{O processo de descoberta da leucemia e seus impactos}

A experiência do adoecimento tem início antes do diagnóstico formal, a partir das interpretações das alterações e sensações corporais, como algo que não vai bem, o que é bem expresso pelo conceito da enfermidade ou adoecimento (illness) que envolve as percepções subjetivas influenciadas pelo contexto sociocultural'2; em contraste com a doença (disease) biomedicamente modelada.

$\mathrm{Na}$ perspectiva do adoecido, os impactos gerados pelo adoecimento crônico concentram-se em uma ruptura e desordem do fluxo da vida, requerendo dos sujeitos, atitudes normalizadoras para reintegrar a vida cotidiana ${ }^{18}$. Vale ressaltar que nem toda mudança orgânica isolada desperta para a experiência de sentir-se mal, sendo assim algumas alterações corporais não incitam à procura do cuidado profissional ${ }^{1}$.

Os primeiros sinais das alterações corporais relatados foram interpretados e incluídos pelos sujeitos no padrão de normalidade ou não, e tratados com base no conhecimento cotidiano através da sua rede de relações. Assim, as manchas, dores de cabeça e mudanças no sono foram interpretados como alterações "normais", corriqueiras que os levaram a procurar orientação e soluções caseiras no seu entorno. Há de lembrar que tais alterações são frequentes em pequenos problemas de saúde e que se resolvem espontaneamente ou com medidas simples, já que a procura por serviços de saúde diante delas resultaria em sobrecargas e intervenções excessivas confluindo para um processo de medicalização.

Como os relatos se referem a fatos passados, foram interpretados e tratados como "normais" naquela ocasião. No entanto, percebe-se uma reinterpretação atual motivada pela experiência e compreendidos, agora, como prenúncios da leucemia diagnosticada.

Assim, o sujeito constrói uma lógica temporal interna única e própria, pela qual atribui sentidos e significados ao tempo vivido no adoecimento, ou seja, a temporalidade experiencial vivenciada pelo adoecido se molda através dessa lógica interna individual, associando ao passado e se locomovendo para o futuro ${ }^{19}$.
Fui acampar em Arenápolis e começou a sair umas manchas pequenas. [...] quando cheguei aqui, em Tangará, fui à farmácia. Eles falaram que era nervoso, porque na época eu era supervisora de vendas. Então, um deles falou: "olha, como você mexe muito com gente, então pode ser nervoso". Aí me deu um Passaneuro ${ }^{\circledR}[\mathrm{e}]$ uma pomadinha para tirar o roxo (Fábia, 26 anos).

Eu não dormia à tarde, eu era muito alerta, eu não dormia. Só que de um tempo para cá eu chegava da escola morrendo de dor de cabeça, muita dor de cabeça, e só queria dormir à tarde, chamava todo mundo da casa da minha tia para dormir: "Vamos dormir". Queria só dormir (Fabiana, 22 anos).

Eu ia jogar bola, quando voltava do jogo ia tomar banho. Aí começava a tremer dentro do banheiro, parecendo vara verde (Fabrício, 27 anos).

A partir da intensificação, do agravamento e da persistência dos sinais e/ou sintomas que começaram a prejudicar ou inviabilizar as atividades diárias (andar, dormir, fazer o trabalho doméstico, higiene pessoal) e a não resolução pelas medidas terapêuticas do sistema de saúde informal, os sujeitos passaram a interpretá-los como problemáticos, o que os fez recorrer ao sistema oficial de saúde. Percebe-se no relato do Fabrício, que a afirmação "tava sem sangue nenhum" pode advir de uma interpretação sobre a leucemia como um problema que afeta o sangue e que foi atualizada pela experiência. Vejamos:

Eu comecei a sentir umas dores aqui assim nas costas, bem no ultimo osso. [...] Acordei de manhã cedo, fui escovar os dentes e quando pisei no chão não consegui, caí duro no chão. Só conseguia ficar assim, respirando. Se eu mexesse um pouquinho, parava de respirar. Fui ficando amarelo, muito anêmico, muito mesmo. Tava sem sangue nenhum. Aí fui para o hospital lá da minha cidade (Fabrício, 27 anos).

Eu comecei com umas manchas roxas no corpo [...]. Foi nas pernas, saiu na barriga, saiu uma no braço também, bem grandona. Aí foi onde eu procurei o médico aqui em Tangará (Fábia, 26 anos).

Eu fui ao médico aqui perto da minha casa, no postinho. Eu fui sozinha. [...] depois que os carocinhos do pescoço e debaixo do braço saíram. Eu me tocando que senti. Fora isso só esses sintomas mesmo a dor de cabeça e sono (Fabiana, 22 anos).

O inicio dos adoecimentos crônicos, por não ter padrões regulares ou previsíveis, faz com que os sujeitos sejam tratados pelos sinais e sintomas pontuais ou recebam diagnósticos equivocados. Tal fato, no entanto, não isenta que os profissionais estejam mais preparados para a suspeita e investigação clínica, principalmente no atendi- 
mento a esta faixa etária que apresenta número expressivo de casos de $\mathrm{LMA}^{20}$.

O diagnóstico equivocado pode provocar impactos emocionais decorrentes das representações mobilizadas sobre enfermidades, não menos graves e estigmatizantes como Lupus e Aids. Soma-se que este período de incertezas, indefinições, em muitos dos casos, representa um grande diferencial entre a vida e a morte, uma vez que a leucemia aguda é uma emergência médica, uma doença agressiva na qual o tempo é primordial ${ }^{17}$. Nos casos dos cânceres, a precocidade na descoberta e início do tratamento, têm influências na sobrevida, no prognóstico, ou seja, no grau de impacto do adoecimento na vida da pessoa, de modo geral. Como referem:

Suspeitaram que era dengue hemorrágica, que era lúpus, que era Aids, que era um monte de doenças, mas nunca iam descobrir que era leucemia. Aí depois daqui [Tangará da Serra] que eu fui para Cuiabá (Fábia, 26 anos).

Fiquei internado lá [Pronto Atendimento no Pará] uns 10 dias e ninguém sabia o que eu tinha, $e$ eu só ficando amarelo, ruim. Todo dia só ia piorando (Fabrício, 27 anos).

Me internaram, deixaram três dias e falaram que era virose (Felipe, 24 anos).

Após percorrerem vários médicos e serem tratados pontualmente, os sujeitos realizaram exames, entre eles o hemograma completo que constou alterações significativas (alta de leucócitos e baixa de plaquetas) que levaram a suspeitar da leucemia, encaminhando para a biópsia da medula óssea e confirmando o diagnóstico.

Este processo, da primeira consulta médica até o diagnóstico definitivo, nos casos em tela, teve em média a duração de 15 a 20 dias, mostrando agilidade da rede pública de saúde, mas vale destacar que a hospitalização favoreceu o acesso e a celeridade dos procedimentos.

Nota-se, contudo, nos relatos, que o tempo da busca por diagnóstico é repleto de inquietação, ansiedade e sofrimentos. Remete à temporalidade do vivido como forma de conduzir o tempo de acordo com os significados dos acontecimentos para o sujeito, distanciando, assim, da sequência cronológica das unidades de saúde ${ }^{19}$.

Fiquei internado lá no Pará uns 10 dias. Chegamos aqui [Cuiabá] já tinha um pessoal esperando a gente, nos levaram direto pro Pronto Socorro. Fiquei 5 dias lá, depois mais 5 dias no Hospital Geral. Ai já fui pro Hospital do Câncer e comecei a fazer o tratamento (Fabrício, 27 anos).

Lá em Sinop, a doutora [X], me encaminhou para o Banco de Sangue. Ela pegou, me atendeu:
"Oh, vou fazer um exame de sangue em você, completo. Daí, depois, elas vão lá te chamar". Eu saí, fiz o exame de sangue completo, fui embora. Um dia depois, passou o dia que eu fui lá... foi na terça, na quarta, na quinta-feira de manhã, me ligaram. Ela ligou e falou que era para eu ir para Cuiabá fazer um exame, só que ela já sabia, mas não falou a verdade. Só que eu fui na outra semana, daí. Levei umas horas, cheguei lá... A doutora [Y], me consultou e deu 99\% de chances de ser leucemia e 1\% de não ser leucemia. Bem dizer, já era leucemia. Daí pegou, consultou, no outro dia comecei a fazer quimioterapia (Felipe, 24 anos).

O diagnóstico formal contribui na construção social do adoecimento, nomeando um conjunto de alterações corporais, imprimindo coerência aos acontecimentos anteriores, ao que vem sendo vivenciado até o momento ${ }^{21}$. Trata-se do processo de tornar-se doente o qual embute uma transição, ou seja, a passagem de uma condição ou estado para outro (no caso, saudável para adoecido) e se refere, tanto ao processo como aos resultados de interações complexas ${ }^{22}$.

Ao comunicar um diagnóstico de câncer são mobilizados, em quem o recebe, ideias e significados do estoque de conhecimentos sobre a enfermidade, podendo provocar impactos e, por isso, se faz necessário um cuidado centrado no adoecido e na forma como a informação é repassada $^{23}$, o que é notável nos seguintes relatos dos sujeitos:

Nem cheguei a entrar na sala do médico, eu cheguei no corredor e ele chamou "você é a Fábia?", eu falei "sim", aí ele falou assim, "olha você está com 93\% da doença, você tem 7\% de chance de vida, a sua luta começa agora. Aquilo, ali, o meu chão caiu (Fábia, 26 anos).

Fiquei sabendo aos poucos porque ela [Mãe] foi me contando de pouco em pouco. As meninas lá, as enfermeiras também começaram a falar como que era, depois que falaram pra mim. Não falaram de uma vez, não (Fabrício, 27 anos).

No contexto internacional, há avançadas discussões que tomam o diagnóstico como objeto de análise sociológica, propondo abordá-lo como categoria, processo e consequência e cuja análise requer considerar os níveis individual, institucional e societal, nos quais operam sem serem excludentes ${ }^{24}$. Destacam-se nos excertos seguintes o diagnóstico como categoria e cujas consequências decorrem das percepções, crenças, conhecimentos de senso comum, significados implícitos da doença e experiências indiretas anteriores com o câncer, bem como o modo singular de reagir frente aos problemas. Trata-se de um momento em 
que se defrontam doença/disease e adoecimento/ illness, paciente e médico, queixa e explicação ${ }^{25}$ gerando, nos casos, sentimentos que modelam uma faceta do impacto do diagnóstico por câncer:

Entrei dentro do banheiro e não queria sair. Eu chorava, chorava, chorava, chorava, e eu não queria sair, não queria sair. E a mulher veio orar para mim, aí que eu fiquei tranquila. Mas eu não queria aceitar, não [...] Um amigo meu tinha falecido com leucemia [...], mas isso há 10 anos atrás. A dele tinha que fazer transplante de medula. Ele fez o transplante, só que deu rejeição. Aí deu rejeição e ele faleceu. Só que assim, eu nunca mais ouvi falar de ninguém. Eu ainda ficava pensando nele, mas nunca imaginei que iria acontecer comigo (Fábia, 26 anos).

Eu não sabia o que era câncer, o que era leucemia, o que era tumor, fui descobrir depois que eu comecei o tratamento. Que há sete, seis anos atrás mais ou menos metade da população não sabia o que era isso (Fabiana, 22 anos).

Entre as reações como expressão do impacto do diagnóstico notam-se a negação, a experiência indireta pela lembrança de amigo que faleceu e que "nunca imaginei que iria acontecer comigo"; e dois sujeitos que nunca tinham ouvido falar de doença até então. Assim, as diferentes reações dos sujeitos estão relacionadas com as significações sobre a doença que permeiam a sociedade e grupos específicos e têm por base os conhecimentos, valores e crenças elaboradas ao longo das suas experiências pessoais e sociais ${ }^{26,27}$.

\section{Impactos na aparência}

A aparência inscreve-se no corpo remetendo à forma com que nos apresentamos aos outros e a nós mesmos, o que não se circunscreve a um plano físico e objetivo, e sim centralmente ao simbólico e intersubjetivo.

Após iniciarem o tratamento quimioterápico endovenoso, com aplicações semanais em média durante oito meses, alguns efeitos colaterais como náusea, ulcerações e vômito foram relatados, mas sobressaiu significativamente a queda de cabelo:

É um baque, é uma coisa que não tem explicação. Você de um dia para o outro você descobre uma doença, de um dia para o outro começar a cair seu cabelo. Eu fiquei careca na primeira quimioterapia, no primeiro tratamento de quimioterapia caiu. Na radioterapia eu já estava com cabelo já, caiu de novo. Eu não me lembro o por quê. E no último tratamento também caiu. Caiu umas três ou quatro vezes o meu cabelo (Fabiana, 22 anos).

Os cabelos são componentes visíveis do rosto - parte do corpo que se impõe nas interações co- tidianas e é prenhe de valores. O rosto representa, tanto objetiva quanto subjetivamente, a identidade, reconhecimento do outro, identificação do sexo, qualidades da sedução, entre outros ${ }^{28}$. Um dano nessa região, de forma temporária ou permanente, possui forte carga simbólica para quem o sofre, pois além de dar visibilidade a sua condição, acaba também modificando o sentimento de identidade ${ }^{29}$. Podemos observar no relato de Felipe, a queda de pelos do corpo (para além das partes visíveis pelos outros) como o impacto mais significativo que tensionava o pertencimento ao ferir o modelo de masculinidade predominante imprimindo-lhe feições femininas.

Tristeza. Não desesperei, fiquei triste. Mas eu sabia que a realidade era aquela: de todo mundo caía [...]. Quando fui tomar banho, passei a mão no cabelo, eu sabia que o cabelo caía, o povo falava, mas eu não acreditava que o meu ia cair. Fui tomar banho, comecei a passar a mão no cabelo, aí começou a cair mesmo. Ai todo dia de manhã, quando acordava, minha cama estava cheia de cabelos (Fabrício, 27 anos).

Durante o tratamento eu fique careca. Fiquei sem sobrancelha, sem cílios, sem cabelo na axila, as pernas lisas... Meu Deus! Fiquei parecendo uma mulher, depilada, totalmente [risos] (Felipe, 24 anos).

Nota-se, também, como o impacto na aparência impele a criar novas formas de viver utilizando estratégias de enfrentamento empreendidas no cotidiano que minimizem as marcas visíveis pela utilização de acessórios como a touca, boné, lenços e perucas. Soma-se que estes acessórios são medicamente recomendados devido à sensibilidade da pele, que fica sujeita a queimaduras pela exposição solar, sendo fundamental para proteger o couro cabeludo ${ }^{17}$.

Estar careca constitui uma marca mais profunda que gera desconforto e os recursos citados disfarçam uma condição não chamando atenção para a aparência, pois o estigma social assentase na visibilidade da marca, propriamente ${ }^{28,30}$. No segundo e terceiro trechos seguintes, o uso de artefatos como peruca e lenços parece ter sido facilitado pelo fato de serem acessórios comuns ao universo feminino, mostrando que elementos de gênero fazem variar o impacto do câncer. Todavia, a região do corpo afetada é mais significativa para um ou outro sujeito do mesmo sexo, como se nota nos casos de Felipe (no trecho anterior) e Fabrício (a seguir).

Resolvi raspar de uma vez só. Eu chorei bastante. Aí, depois, minha mãe já comprou uma touca pra mim. Aí eu vivia de touca e de boné. Eu não gostava de ficar careca (Fabrício, 27 anos). 
Eu tinha o cabelo loiro, ai eu queria uma peruca loira. Aí eu cheguei em Tangará, fui lá comprar uma peruca loira. O cabelão bem grandão (Fábia, 26 anos).

Tinha vários lenços que usava na cabeça, tinha para o dia, para a tarde e para a noite usava combinando com minhas roupas ou sapato, fazia maior sucesso (Fabiana, 22 anos).

O próximo relato contém sutil contraponto ao não se incomodar pelos olhares alheios, a não ser quando eles se prolongam e ainda que se saliente o tratamento como justificativa da aparência. Ademais, mostra como as interações no grupo de pertença permitem um retrato mais realístico das qualidades e não apenas um julgamento antecipado de desacreditado devido às marcas isoladas ${ }^{30}$, ou seja, aqueles que têm a oportunidade de conhecer a pessoa adoecida (e não apenas o doente de câncer) pelo contato cotidiano (no bairro, "o povo") visualizam outras informações e características.

Eu nunca tive preconceito dos outros olharem. O meu negócio é não olhar muito. Se olhasse muito eu já falava "O que você está olhando?", entendeu? Eu já falava "Por que está olhando?", "Estou tratando". Era assim, mas eu não tinha vergonha nenhuma. Tanto que aqui no bairro mesmo, o povo já sabia que eu fazia tratamento, eu andava sem chapeuzinho, sem peruca, sem nada, eu andava careca (Fabiana, 22 anos).

Outro impacto da LMA foi notado em relação à aparência pelo tamanho do corpo. A corpulência em geral é valorizada em segmentos populares em que o corpo é utilizado numa visão prática de utilidade, onde a força física é requisitada para desempenhar as ocupações cotidianas ${ }^{29}$, porém tal valorização não ocorre de forma absoluta, mas relativizada, como ilustra o segundo trecho, pela a artificialidade do aumento de peso provocado pelo inchaço.

Engordei 20 quilos, e não consegui emagrecer até hoje (Fábia, 26 anos).

Teve uma época que eu fiquei bem redondo. Não era gordo, não, era redondo de inchaço. Não podia comer muita coisa com sal, por causa do corticoide (Felipe, 24 anos).

Em outro extremo, a magreza também constitui impacto. As concepções de saúde em segmentos populares atrelam-se à força, logo, "magreza" e "fraqueza" aludem às debilidades físicas e morais provocadas pela doença e tratamento que não são dissociados ${ }^{29}$. Observa-se a importância da aparência, sendo que um dos sujeitos ressalta que frequentava "academia" e teve que parar. Em se tratando de adultos jovens, como nos casos analisados, é conhecida a crescente importância atribuída por eles à aparência corporal, através de uma idealização do corpo, tornando-se um objeto de consumo e de investimento ${ }^{31}$.

Perdi muito peso. Ficava na linha dos trinta e cinco, no máximo quarenta, não passava dos quarenta. Teve uma época que eu fiquei bem magrinha mesmo, só a capa. Vamos dizer assim, só o coro e o osso (Fabiana, 22 anos).

Eu era gordinho, meio troncadinho, fazia academia, aí comecei a tomar a quimio e esses negócios. Parei de fazer academia. Aí fiquei só o palito. Também não conseguia comer, quando eu tava lá no hospital mesmo. Quando eu sentia o cheiro daquelas comidas lá, eu já vomitava tudo, ficava com enjôo (Fabrício, 27 anos).

Vale ressaltar nos relatos acima, que além do mal-estar estomacal ocasionado pela quimioterapia, há ainda a alimentação de hospital baseada, predominantemente, nos aspectos técnicos dos nutrientes, em detrimento desse momento como fonte de prazer, tornando-se obrigação insuportável pelas características que não agradam ao prazer gustativo ${ }^{32}$. Enfim, entende-se que além do mal-estar pelos medicamentos, o contexto hospitalar e seus correlatos mobilizam representações que podem exacerbar os impactos do adoecimento.

\section{Iminências da morte e seus impactos}

O histórico potencial de letalidade permeia as representações deste tipo de adoecimento e geram tensões quando mobilizados pelas experiências indiretas que a comprovam (morte de pessoas conhecidas), mas também podem ser relativizadas pela experiência própria como sobrevivente, o que não se faz sem incertezas como, analogamente, verificou estudo sobre leucemia mieloide crônica ${ }^{27}$.

A morte não é unívoca, nem é tratada igualmente para todos, havendo diferenciações frente ao moribundo remetendo à percepção do valor social do sujeito ${ }^{33}$, como visto na presente pesquisa devido ao tipo de enfermidade e à idade do adoecido.

Contudo, se a morte parece incoerente nesta fase da vida, pode ser relativizada diante do sofrimento que carrega, como notamos no trecho:

Quando a Bruninha morreu, [paciente que tinha 6 anos] foi tudo tão diferente.... Não houve gritaria, nem choros desesperadores pelo corredor do hospital, como sempre acontece. Não, eles foram discretos, viram que foi melhor assim, porque ela descansou, aqui ela estava sofrendo demais. A mãe 
dela mesmo falou isso pra mim. Sofrendo demais... (Felipe, 24 anos).

$\mathrm{Na}$ especificidade deste estudo, as mortes e suas ameaças estiveram presentes nas biografias dos sujeitos enfaticamente em dois momentos: perdas de amigos durante o tratamento e percepção da possibilidade da própria morte nas intercorrências. A morte embute o sentimento de perda e, convivendo com a leucemia, o sujeito se depara com várias outras perdas, de diversas dimensões e complexidades. Seriam as pequenas mortes, mortes miúdas e seus impactos?

Observa-se a seguir, como a morte dos amigos trouxe ao seu cotidiano esta possibilidade, até então, remota, vista como tabu e restrita apenas aos comentários da família - ideia essa evitada, encoberta e empurrada para a clandestinidade na sociedade moderna ${ }^{34}$.

[...] eu tinha um monte de amigos. Aí um morreu segunda, outro na terça lá dentro da Casa de Apoio onde eu tava. Aí na quarta morreu um amigo que tava internado no Hospital de Câncer. Na quarta-feira, quando eu chego, eu já fiquei chorando a noite toda, falando pra minha mãe que eu era o próximo. Aí veio a cozinheira de lá, que é minha amiga até hoje, veio a psicóloga, a minha mãe, os voluntários, um monte de gente conversar comigo, falando que não era assim. Aí me explicaram tudinho lá, porque cada um morreu. Mas, mesmo assim, continuei chorando muito, porque eu achava que porque eles foram, era minha vez também (Fabrício, 27 anos).

O sentimento de impotência diante a morte do outro "configura-se como a vivência da morte em vida. É a possibilidade de experiência da morte que não é a própria, mas é vivida como se uma parte nossa morresse, uma parte ligada ao outro pelos vínculos estabelecidos" ${ }^{\prime 35}$. Adoecidos se sentem unidos, se identificam como pertencentes ao mesmo grupo, com uma identidade comum pela doença.

Algumas situações mobilizaram mais enfaticamente a ideia da possibilidade de morte, em que as sensações corporais e sinais objetivos (sangue, feridas) foram interpretados como prenúncios da morte, ou seja, sua proximidade expressa pelas intercorrências e agudização:

[...] foi a única vez que eu tive sangramento pelo nariz. Sem mais sem menos, eu estava conversando com as visitas no quarto [...] e eu comecei a sangrar pelo nariz. Gente! Aquilo ali foi desesperador que eu lembro até hoje. Naquele dia eu falei "Ah, meu, eu vou morrer, já estou sangrando, eu vou morrer..." (Fabiana, 22 anos).
Chamaram até meus parentes, achando que eu ia... que eu ia morrer. Meus parentes vieram me ver. Com a boca cheia de ferida... O sangue coagulou aqui, ficou preso aqui, tudinho... [mostra com a mão a parte da boca e do estômago]. Demorou uns dias, fiquei lá uns seis dias que eu estava internado no isolamento, que eu fui vomitar tudo para fora [...]. Eu vomitei parecia fígado.... Misturados com uns pedacinhos dentro [...] O sangue foi travando aqui [novamente com a mão o estômago] (Felipe, 24 anos).

$\mathrm{Na}$ experiência de adoecimento, parâmetros culturais, pessoais, biográficos guiam a relação do sujeito com a morte e suas ameaças, influenciando impactos da sua insistente presença. Os discursos apresentam o concreto, o palpável da morte, episódios que trouxeram à tona a fragilidade do ser humano e sua finitude ${ }^{35}$.

\section{Considerações finais}

A investigação sobre experiência de adoecimento de longa duração possibilita o reconhecimento de impactos e as intermediações de diferentes ordens que os exacerbam ou amenizam.

Em adoecimento com alta letalidade como a LMA, seus impactos são sentidos e interpretados de diferentes formas, mas também mobilizam ações (práticas e interpretativas) para lidar cotidianamente com eles, cujo substrato advém de interações sociais (históricas, pessoais, institucionais) que se desenrolam no mundo da vida pré-existente.

É o caso dos nossos interlocutores que sobreviveram, tanto à uma doença historicamente ameaçadora, quanto ao tratamento reconhecidamente agressivo. Se assim, sob o ponto de vista clínico, o "fora de tratamento" correspondência à cura, não se ignora a presença da incerteza que é, ordinariamente, observada nos estudos de experiência de adoecimentos de longa duração, constituindo impacto marcante que alcança a identidade dos sujeitos.

Nos impactos, destacam-se peculiaridades do grupo de pertença (adultos jovens), como os valores e projetos típicos a ele inerentes, postas pela fase da vida em que o adoecimento irrompe, tendo como momento de inflexão o diagnóstico formal.

Somam-se os impactos na aparência que reportam à indissociabilidade dos aspectos materiais e simbólicos em síntese no corpo em que valores encarnados são afetados. Não obstante, as 
associações não são homogêneas, por exemplo na queda de pelos e cabelos, aludem às intersecções geracionais e de gênero no impacto da leucemia.

Por fim, a presença concreta ou ameaçadora da morte parece constituir-se em perdas geradoras de impactos importantes nos projetos interrompidos, não concretizados, adiados ou ajustados, no surgimento ou agravamento do adoecimento de longa duração, rompimentos de relações e rotinas e, finalmente, a morte de amigos.
Os impactos decorrem das conseqüências de algo novo introduzido numa dada realidade. No caso dos adoecimentos de longa duração e da leucemia, aqui em parte analisada, os impactos seriam os efeitos e transformações provocadas na vida das pessoas e seu entorno - dos próprios adoecidos, familiares, profissionais - e evocam (re) ações. Contudo, há de lembrar que os impactos se diluem na experiência compondo-a, e não sendo homogênea, sua abordagem privilegia a singularidade inscrita em biografias contextualizadas.

\section{Colaboradores}

RA Barsaglini orientou, redigiu e revisou o texto. BBNS Soares coletou os dados, redigiu e revisou o texto.

\section{Agradecimentos}

Agradecemos à Coordenação de Aperfeiçoamento de Pessoal de Nível Superior - CAPES -, pela concessão de bolsa de Mestrado. 


\section{Referências}

1. Rabelo MCM, Alves PCB, Souza IMA. Experiência de doença e narrativa. Rio de Janeiro: Fiocruz; 1999.

2. Alves PC A fenomenologia e as abordagens sistêmicas nos estudos sócio-antropológicos da doença: breve revisão crítica. Cad Saude Publica 2006; 22(8):1547-1554.

3. Bondía JL. Notas sobre a experiência e o saber de experiência. Rev Bras de Educ 2002; 19:20-28.

4. Le Breton D. Antropologia dos sentidos. Petrópolis: Ed. Vozes; 2016.

5. Canesqui AM, organizador. Olhares socioantropológicos sobre os adoecidos crônicos. São Paulo: Hucitec/Fapesp; 2007.

6. Barsaglini RA. Adoecimentos crônicos, condições crônicas, sofrimentos e fragilidades sociais: algumas reflexões. In: Canesqui AM, organizador. Adoecimentos e sofrimentos de longa duração. $2^{\text {a }}$ ed. São Paulo: Hucitec; 2015. p. 78-101.

7. Corbin J, Strauss A. Managing chronic illness at home: three lines of work. Qualitative Sociology 1985; 8(3):224-247.

8. Raynaut C. Interfaces entre a antropologia e a saúde: em busca de novas abordagens conceituais. Rev Gaúcha Enferm 2006; 27(2):149-165.

9. Schutz A. Bases da fenomenologia. In: Wagner H, organizador. Fenomenologia e relações sociais: textos escolhidos de Alfred Schutz. Rio de janeiro: Zahar; 1979. p. 61-70.

10. Lubkin IM, Larsen P. What is chronicity? In: Lubkin IM, Larsen P, organizadores. Chronic illness: impact and interventions. 5a ed. Sudbury: Jones \& Barlett Lerning; 2002. p. 3-24.

11. Siqueira BBN. Experiência de adoecimento por adultos jovens com Leucemia [dissertação]. Cuiabá: Universidade Federal de Mato Grosso; 2014.

12. Gomes R. Análise e interpretação de dados de pesquisa qualitativa. In: Minayo MCS, Deslandes SF, Gomes R, organizadores. Pesquisa Social: teoria, método e criatividade. 30ª ed. Petrópolis: Vozes; 2011. p. 79-108.

13. Cardoso RCL, Sampaio H. Estudantes universitários e o trabalho. Revista Brasileira de Ciências Sociais 1994; 9(26):30-49.

14. Franch M. Tempos, passatempos e contratempos. Um estudo sobre práticas e sentidos do tempo entre jovens de grupos populares do Grande Recife [tese]. Rio de Janeiro: Universidade Federal do Rio de Janeiro; 2008.

15. Trezza MCSF. Construindo através da doença possibilidades de sua libertação para uma outra forma de viver: um modelo teórico representativo da experiência de pessoas que tiveram câncer [tese]. Rio de Janeiro: Escola de Enfermagem Anna Nery; 2002.

16. Montagner MI. Mulheres e câncer de mama: experiência e biografia cindidas [tese]. Campinas: Universidade Estadual de Campinas; 2011.

17. Instituto Nacional do Câncer (INCA). $A B C$ do câncer: abordagens básicas para o controle do câncer. Rio de Janeiro: Inca; 2012.

18. Lira GV, Nations MK, Catrib AMF. Cronicidade e cuidados de saúde: o que a antropologia da saúde tem a nos ensinar. Texto Contexto Enferm. 2004; 13(1):147155.

19. Dolina JV, Bellato R, Araújo LFS. Diferentes temporalidades no adoecimento por câncer de mama. Rev Esc Enferm USP 2014; 48(2):77-84.
20. Carvalho QGS, Pedrosa WA, Sebastião QP. Leucemia mieloide aguda versus ocupação profissional: perfil dos trabalhadores atendidos no Hospital de Hematologia de Recife. Rev Esc Enferm USP 2011; 45(6):1446-1451.

21. Pinder R. Coherence and incoherence: doctors and patients" perspectives on the diagnosis and Parkinson's Disease. Sociology of Health \& Illness 1992; 14(1):1-23.

22. Luz EL, Basto ML. The opinion of patients with COPD: the process of becoming chronically sick. Cien Saude Colet 2013; 18(8):2221-2228.

23. Skaba MMVF. Compreendendo a trajetória de mulheres em busca do diagnóstico e tratamento do câncer de mama: uma perspectiva sócio-antropológica [tese]. Rio de Janeiro: Fundação Oswaldo Cruz; 2003.

24. Jutel A, Nettleton S. Towards a sociology of diagnosis: Reflections and opportunities. Soc Sci Med 2011; 73(6):793-800.

25. Jutel A. Sociology of diagnosis: a preliminary review. Sociology of Health and Illness 2009; 31(2):278-299.

26. Silva CA, Carvalho LS, Santos ACPO, Menezes MR. Vivendo após a morte de amigos: História oral de idosos. Texto Contexto Enfermagem 2007; 16(1):97-104.

27. Lopes YAA, Trad LAB. Modos peculiares e lidar com os riscos, incertezas e rupturas no convívio com a LMC: duas experiências singulares. In: Castellanos MEP, Trad LAB, Jorge MSB, Leitão IMTA, organizadores. Cronicidade: experiência de adoecimento e cuidado sob a ótica das Ciências Sociais. [e-book]. Fortaleza: EdUECE; 2015. p. 194-224.

28. Le Breton D. Sociologia do corpo. Petrópolis: Vozes; 2010.

29. Canesqui A M. Mudanças e Permanências da Prática Alimentar Cotidiana de Famílias de Trabalhadores. In: Canesqui AM, Garcia RWD, organizadores. Antropologia e Nutrição: um diálogo possível. Rio de Janeiro: Ed. Fiocruz; 2005. p. 167-210.

30. Goffman E. Estigma: notas sobre a manipulação da identidade deteriorada. $4^{\text {a }}$ ed. Rio de Janeiro: LTC Editora; 1988.

31. Iriart JAB, Chaves JC, Orleans RG. Culto ao corpo e uso de anabolizantes entre praticantes de musculação. Cad Saude Publica 2009; 25(4):773-782.

32. Corbeu JP. Alimentar-se no Hospital: as dimensões ocultas da comensalidade. In: Canesqui A M, Garcia RWD, organizadores. Antropologia e Nutrição: um diálogo possível. Rio de Janeiro: Ed. Fiocruz; 2005. p. 227238.

33. Herzlich C. Os encargos da morte. Rio de Janeiro: UERJ; 1993. Série Estudos em Saúde Coletiva.

34. Bellato R, Carvalho EC. O jogo existencial e a ritualização da morte. Rev Latino-am Enfermagem 2005; 13(1):99-104.

35. Kovács MJ. Educação para a Morte: um Desafio na Formação de Profissionais de Saúde e Educação [tese]. São Paulo: Universidade de São Paulo; 2002.

Artigo apresentado em 21/06/2017

Aprovado em 19/07/2017

Versão final apresentada em 21/07/2017 